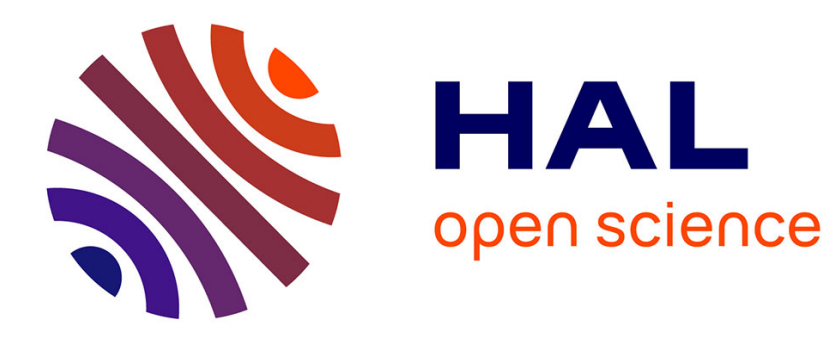

\title{
Degradation of MIOS memory structures
}

\author{
A. El-Dessouky, P. Balk
}

\section{To cite this version:}

A. El-Dessouky, P. Balk. Degradation of MIOS memory structures. Revue de Physique Appliquée, 1978, 13 (12), pp.833-835. 10.1051/rphysap:019780013012083300 . jpa-00244556

\section{HAL Id: jpa-00244556 https://hal.science/jpa-00244556}

Submitted on 1 Jan 1978

HAL is a multi-disciplinary open access archive for the deposit and dissemination of scientific research documents, whether they are published or not. The documents may come from teaching and research institutions in France or abroad, or from public or private research centers.
L'archive ouverte pluridisciplinaire HAL, est destinée au dépôt et à la diffusion de documents scientifiques de niveau recherche, publiés ou non, émanant des établissements d'enseignement et de recherche français ou étrangers, des laboratoires publics ou privés. 


\title{
DEGRADATION OF MIOS MEMORY STRUCTURES
}

\author{
A. EL-DESSOUKY and P. BALK \\ Institute for Semiconductor Electronics/SFB 56 « Festkörperelektronik », \\ Technical University, 5100 Aachen, Federal Republic of Germany
}

\begin{abstract}
Résumé. - L'étude comparative du décalage de fenêtre pendant le cycle d'écriture et d'effacement des systèmes MAOS et MNOS montre une forte dépendance par rapport à l'épaisseur du $\mathrm{SiO}_{2}$. Le système MNOS fait preuve d'une plus grande stabilité. La combinaison MANOS (recuisson à l'oxygène) est comparable à cet égard à celle de MNOS. Les résultats sur l'accroissement de la densité des états rapides de surface et sur la rétention des charges seront présentés. Les dates suggèrent que l'eau influence le phénomène de dégradation.
\end{abstract}

Abstract. - A comparative study of window shift during write/erase cycling of MAOS and MNOS devices shows strong dependence in the shift on $\mathrm{SiO}_{2}$ thickness, the MNOS devices showing better stability. Their combination MANOS $\left(\mathrm{O}_{2}\right.$ annealed $)$ is comparable in this respect to MNOS. Results on the increase of fast surface state density and on charge retention are reported. The data suggests that $\mathrm{H}_{2} \mathrm{O}$ affects the degradation phenomena.

1. Introduction. - The attractive properties of Metal-Insulator- $\mathrm{SiO}_{2}$ on $\mathrm{Si}$ (MIOS non-volatile memory devices for EAROM application) are partially offset by the degeneration of the memory under repeated write-erase operation [1]. This degeneration, a shift of the flat band voltage $\left(V_{\mathrm{FB}}\right)$ characterizing the two logical states of the device which define its memory window, takes place in the gate structure of the device. Thus it is of interest to investigate the MIOS-gate capacitor under repeated write-erase $(w / e)$ cycling. Limiting the investigation to MIOS capacitors not only facilitates the sample preparation, but also simplifies a comparison to investigations on Negative Bias Stress (NBS) of MOS capacitors [2, 3, 4].

It has been reported that the degradation of MNOS memory devices is accompanied by an increase in the density of fast surface states $\left(N_{\mathrm{ss}}\right)$ and a reduced charge storage time [1]. For transistors a negative shift, of the threshold window [2, 3], for capacitors a positive shift of the flat band windown $[2,4]$ has been observed. According to one proposal this shift is caused by the drift of $\mathrm{OH}$ groups in the thin $\mathrm{SiO}_{2}$ layer and should be dependent on its thickness [4].

This paper will present data on a comparative study of this reliability problem for MNOS and MAOS structures and their dependence on the $\mathrm{SiO}_{2}$ thickness. The reliability of the new MANOS structure [8] will be compared to that of MNOS and MAOS. The effect of $\mathrm{O}_{2}$ annealing of $\mathrm{Al}_{2} \mathrm{O}_{3}$ on the reliability of MAOS and MANOS devices will be demonstrated.

2. Experimental. - 2.1 SAMPLE PREPARATION. MAOS and MNOS samples with $\mathrm{SiO}_{2}$ layers of different thicknesses (between 1.2 and $5 \mathrm{~nm}$ ) were fabricated. The oxidation of the $\langle 100\rangle$ oriented $10 \Omega \mathrm{cm}$ silicon substrates was carried out in a mixture of $10 \% \mathrm{O}_{2}$ in $\mathrm{N}_{2}$ at the deposition temperature of the next layer. The $\mathrm{Si}_{3} \mathrm{~N}_{4}$ and $\mathrm{Al}_{2} \mathrm{O}_{3}$ layers were prepared pyrolytically at $900^{\circ} \mathrm{C}$ using the $\mathrm{SiH}_{4}-\mathrm{NH}_{3}-\mathrm{H}_{2}-\mathrm{N}_{2}$ and the $\mathrm{AlBr}_{3}-\mathrm{NO}-\mathrm{H}_{2}-\mathrm{N}_{2}$ systems respectively. MANOS capacitors were fabricated using the same technologies. Some of the MAOS and MANOS samples were annealed before metallization in a pure $\mathrm{O}_{2}$ atmosphere for $15 \mathrm{~min}$ at the deposition temperature. Al dots were evaporated through a mask in an e-gun apparatus. Annealing of the Al contacts in $\mathrm{N}_{2}$ for $15 \mathrm{~min}$ at $450^{\circ} \mathrm{C}$ concluded the fabrication process.

2.2 Measuring SET-UP. - Wear-out measurements were carried out using an automatic system (Fig. 1); which measures the window shift of MIOS capacitors during $w / e$ cycling. The $w / e$ operation is interrupted periodically for a one second pause to measure and directly record the two $V_{\mathrm{FB}}$ values which define the logical window. The number of $w / e$ cycles in which the window has shifted by an unacceptable amount will be designated as $Z_{w / e}^{\prime}$ (see Fig: $2 a$ ). In this work, the

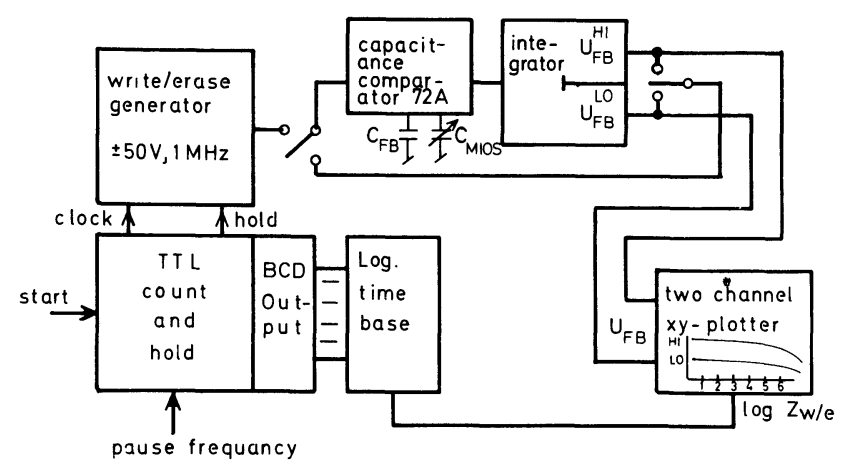

FIG. 1. - Block diagram of automatic measurement system for window shift. 


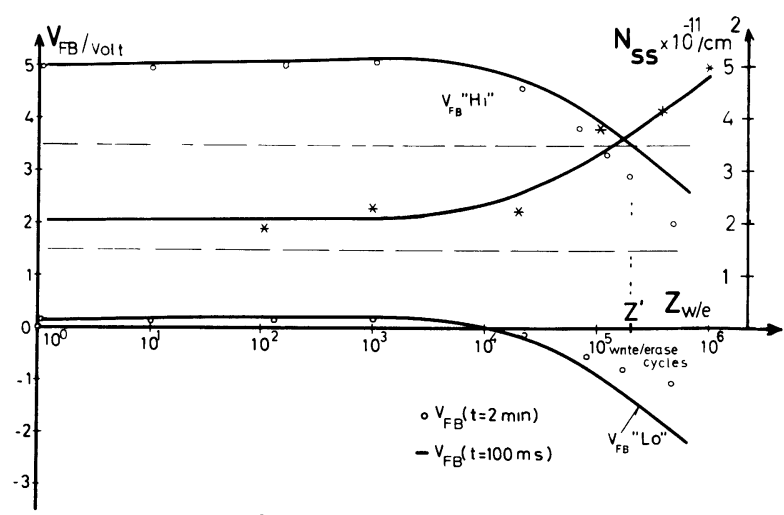

FIG. 2. - Window shift $(a)$ and $N_{\mathrm{ss}}$ change (b) of MAOS capacitors. Gate pulse cycle +22 and $-42 \mathrm{~V}$ for $10 \mathrm{~ms}$.

window size i.e. the difference between the two logical $V_{\mathrm{FB}}$ states, was chosen to be $5 \mathrm{~V}$. This value is not only TTL compatible but also lies near the minimum retention margin of $4 \mathrm{~V}$ [10]. Along with the window shift measurement the density of the fast surface states $N_{\text {ss }}$ was determined by the Gray and Brown method [9].

Before measuring the window degeneration or retention time of a virgin MAOS or MANOS capacitor it was stressed with negative pulses to saturate the electron injection from the metal electrode [11]. Otherwise the bistable states of the memory window will shift in positive direction due to this anomalous charging during erase operations. The magnitude of the positive shift depends on the erase pulse width.

The charge retention for the different structures was determined before and after performing the window shift measurements by checking the $V_{\mathrm{FB}}$ values as a function of storage time at room temperature. The samples were short-circuited before and after the $V_{\mathrm{FB}}$ check.

3. Results. - 3.1 ReLATIONSHIP BetweEn $Z_{w / e}^{\prime}, \mathrm{N}$ AND $\mathrm{SiO}_{2}$ THICKNESS. - The logical window for MAOS devices shifted in negative direction for repeated $w / e$ cycling (Fig. 2a); in MNOS devices the shift was in opposite direction. Parallel with this shift $N_{\text {ss }}$ on MAOS increases, as indicated in figure $2 b$. The increase in $N_{\mathrm{ss}}$ for MNOS devices is small in comparison and depends on the fabrication procedure : The

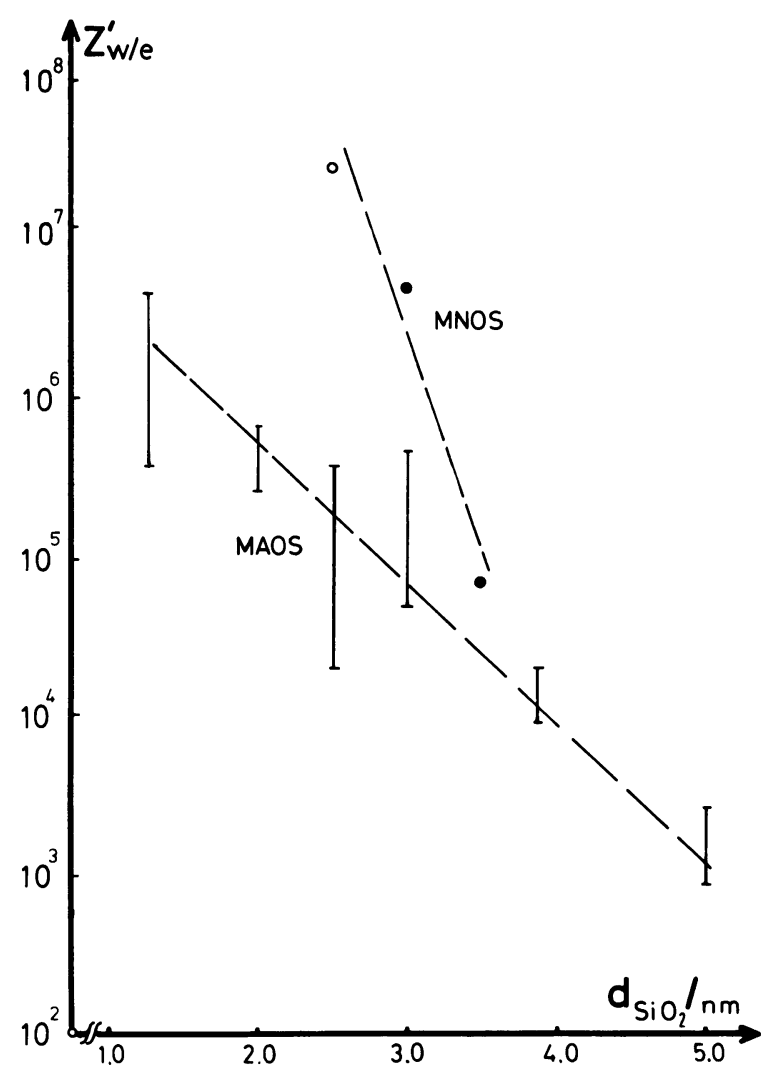

FIG. 3. - Number of write/erase cycles $Z_{w / e}^{\prime}$ (constant window size) for MAOS and MNOS capacitors and different $d_{\mathrm{SiO}_{2}}$;

$$
d_{\mathrm{Si}_{3} \mathrm{~N}_{4}}=d_{\mathrm{Al}_{2} \mathrm{O}_{3}}=84 \mathrm{~nm} \text {; }
$$

write/erase pulse length $10 \mathrm{~ms}$.

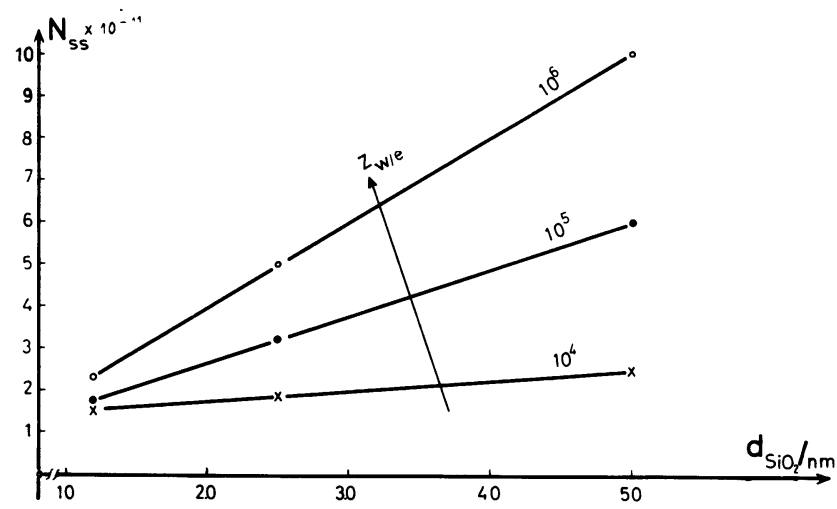

FIG. 4. - Density of fast surface states $v s$ thickness of $\mathrm{SiO}_{2}$ on MAOS-capacitors for constant initial $\mathrm{SiO}_{2}$ field

$$
E_{0 \mathrm{x}}^{0}=9.86 \mathrm{MV} / \mathrm{cm} \text {. }
$$

Parameter : $Z_{w / e}$. Structure data : Al electrode, $d_{\mathrm{Al}_{2} \mathrm{O}_{3}}=84 \mathrm{~nm}$, $d_{\mathrm{SiO}_{2}}$ as indicated, p-Si substrate $; 10 \Omega \mathrm{cm}$.

TABLE I

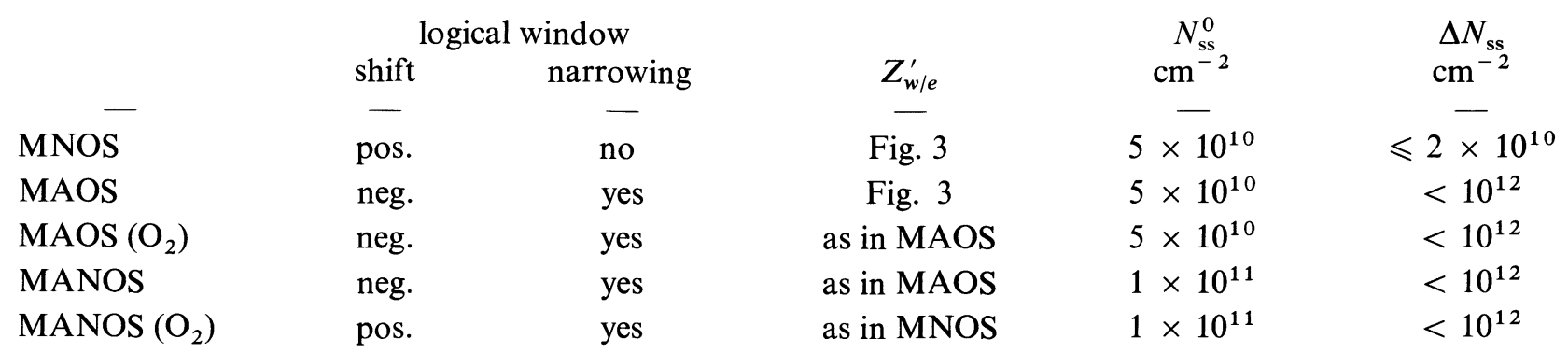


increase for capacitors on which oxide growth and nitride deposition were carried out in situ was very small $\left(\Delta N_{\mathrm{ss}} \leqslant 2 \times 10^{10}\right)$, for devices fabricated in separate oxidation and deposition furnaces the increase was somewhat larger $\left(\Delta N_{\mathrm{ss}} \leqslant 1 \times 10^{11}\right)$. From figure $3, Z_{w / e}^{\prime}$ may be seen to become larger for thinner $\mathrm{SiO}_{2}$ layers; this thickness dependence is more pronounced for MNOS than for MAOS devices. The larger increase in $N_{\text {ss }}$ for thicker $\mathrm{SiO}_{2}$ films is not simply caused by the larger field required for erasure in these cases : figure 4 shows that the effect also occurs at fixed value of the initial field across the $\mathrm{SiO}_{2}\left(E_{0 x}^{0}\right)$. MANOS devices (the insulator structure was prepared in three separate furnaces) behave like MAOS structures with regard to window shift and $N_{\mathrm{ss}}$. A summary of these results is presented in table $\mathrm{I}$.

3.2 EFFECT OF $\mathrm{O}_{2}$ ANNEALING IN MAOS AND MANOS. - MAOS capacitors with $2.5 \mathrm{~nm}$ of $\mathrm{SiO}_{2}$ and $84 \mathrm{~nm}$ of $\mathrm{Al}_{2} \mathrm{O}_{3}$ on p-Si substrates were annealed in $\mathrm{O}_{2}$ at the deposition temperature for times from 5 to $30 \mathrm{~min}$. This treatment causes the minimum positive gate voltage required for negatively charging (write threshold) to increase ; the opposite " erase threshold " remains unaffected. $Z_{w / e}^{\prime}$ drops off exponentially with annealing time in $\mathrm{O}_{2}$. For a $15 \mathrm{~min}$, anneal this effect amounts to 2 decades.

On the other hand, $\mathrm{O}_{2}$ annealing of a MANOS structure with $2.5 \mathrm{~nm}$ of $\mathrm{SiO}_{2}, 20 \mathrm{~nm}$ of $\mathrm{Si}_{3} \mathrm{~N}_{4}$ and $60 \mathrm{~nm}$ of $\mathrm{Al}_{2} \mathrm{O}_{3}$ was found to reduce both thresholds and make the write-erase voltages more symmetrical. The window shift for repeated write-erase cycling is positive and comparable to that for MNOS devices. However, in the MANOS case there is a clear increase in $N_{\text {ss }}$.

3.3 WINDOW RECOVERY. - The positive window shift in MNOS and $\mathrm{O}_{2}$ annealed MANOS devices recorvers when interrupting the write/erase operation. In fact, already during the pause required for reading a perceptible recovery is observed. The $Z_{w / e}^{\prime}$ values in table I were obtained for 20 readings per decade of $Z_{w / e}$. Complete recovery at room temperature requires times in the order of $10 \mathrm{~min}$.

For MAOS and unannealed MANOS devices recovery of the window and elimination of $\Delta N_{\mathrm{ss}}$ requires an annealing treatment in $\mathrm{N}_{2}$ or room air above room temperature. As an example, complete recovery occurs in $15 \mathrm{~min}$ at $200^{\circ} \mathrm{C}$, in $45 \mathrm{~min}$, at $120^{\circ} \mathrm{C}$.

3.4 Charge Retention. - Charge retention measurements for the larger positive logical $V_{\mathrm{FB}}$ state before and after applying $Z_{w / e}^{\prime}$ write-erase pulses gave the following results : For MNOS no change was detected, for MAOS (unannealed) and - MANOS (unannealed) a very slight deterioration and for MAOS $\left(\mathrm{O}_{2}\right.$-annealed) a somewhat larger degradation. Surprisingly, for MANOS $\left(\mathrm{O}_{2}\right.$-annealed $)$ the $V_{\mathrm{FB}}$ value, which before annealing decreased with time, increased very slightly with time after write-erase cycling.

4. Discussion. - From our data it is clear that the maximum tolerable number of $w / e$ cycles depends on the nature of the structure. Thicker $\mathrm{SiO}_{2}$ films lead to decreased $Z_{w / e}^{\prime}$ values. The largest values were obtained for MNOS and $\mathrm{O}_{2}$-annealed MANOS devices. The data for annealed and unannealed MANOS devices indicate that there is no inherent relation between window shift and $\Delta N_{\mathrm{ss}}$. The more rapid degradation of MAOS devices may be caused by the larger erasure fields.

MNOS devices with the double insulator prepared in one furnace without exposing the $\mathrm{SiO}_{2}$ film to room ambient exhibit the smallest $\Delta N_{\text {ss }}$ values. This finding and the (predicted) dependence on $\mathrm{SiO}_{2}$ thickness suggests that water ( $\mathrm{OH}$ groups) does indeed play a role in the creation of fast surface states. The larger $\Delta N_{\text {ss }}$ values for MAOS would follow from the relatively large water pressure in the $\mathrm{Al}_{2} \mathrm{O}_{3}$ deposition process. Although the $\mathrm{SiO}_{2}$ layer in the MANOS structures had been exposed to room ambient the large increase in $N_{\mathrm{ss}}$ would require that additional $\mathrm{OH}$ had penetrated through the $\mathrm{Si}_{3} \mathrm{~N}_{4}$ during $\mathrm{Al}_{2} \mathrm{O}_{3}$ deposition. However, the present data do not permit to draw definitive conclusions on this topic.

From an overall point of view, it appears that MNOS and $\mathrm{O}_{2}$ annealed MANOS devices present the most favorable combination of properties. Particularly in the latter case it may be expected that continued technological studies will lead to further improvement in their behavior.

\section{References}

[1] Balk, P. S. S., Devices (Inst. of Physics, Conf.) Series 19 (1973) 51.

[2] Woods, M. and Tuska, S., 10th Ann. Proc. Rel. Phys. (1972) 120.

[3] Cricchi, J. and Reed, W., 19th Ann. Proc. Rel. Phys. (1971) 1.

[4] Jeppson, K. and Svensson, Ch., J. Appl. Phys. 48 (1977) 2004.

[5] ZIRINSKY, S., J. Electron. Mat. 4 (1975) 591.

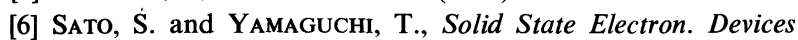
17 (1974) 367.
[7] Tsang, P. and Shepard, J., Electrochem. Soc. (ext. Abstracts) 75-2 (1975) 323.

[8] Stephany, F., Schumacher, M. and Balk, P., these Proceedings.

[9] Brown, D. and Gray, D., J. Electrochem. Soc. 115 (1968) 760.

[10] Frohman-Bentchkowsky, P., Proc. IEEE 58 (1970) 1207.

[11] Balk, P. and Stephany, F., J. Electrochem. Soc. 118 (1971) 1634. 